\title{
Cooling cows efficiently with sprinklers: Physiological responses to water spray
}

\author{
Jennifer M. Chen, ${ }^{*}$ Karin E. Schütz, $†$ and Cassandra B. Tucker ${ }^{* 1}$ \\ *Department of Animal Science, University of California, Davis 95616 \\ †AgResearch Ltd., Hamilton 3240, New Zealand
}

\begin{abstract}
Dairies in the United States commonly cool cattle with sprinklers mounted over the feed bunk that intermittently spray the cows' backs. These systems use potable water - an increasingly scarce resource-but there is little experimental evidence about how much is needed to cool cows or about droplet size, which is thought to affect hair coat penetration. Our objectives were to determine how sprinkler flow rate and droplet size affect physiological measures of heat load in a hot, dry climate, and to evaluate cooling effectiveness against water use. The treatments were an unsprayed control and 6 soaker nozzles that delivered four 3-min spray applications of $0.4,1.3$, or $\geq 4.5 \mathrm{~L} /$ min (with 2 droplet sizes within each flow rate) and resulting in 30 to $47 \%$ of spray directly wetting each cow. Data were collected from high-producing lactating Holsteins $(\mathrm{n}=19)$ tested individually in ambient conditions (air temperature $=31.2 \pm 3.8^{\circ} \mathrm{C}$, mean \pm standard deviation). Cows were restrained in headlocks for $1 \mathrm{~h}$ and received 1 treatment/d for $3 \mathrm{~d}$ each, with order of exposure balanced in a crossover design. When cows were not sprayed, physiological measures of heat load increased during the 1-h treatment. All measures responded rapidly to spray: skin temperature decreased during the first water application, and respiration rate and body temperature did so before the second. Droplet size had no effect on cooling, but flow rate affected several measures. At the end of $1 \mathrm{~h}, 0.4 \mathrm{~L} /$ min resulted in lower respiration rate and skin temperature on directly sprayed body parts relative to the control but not baseline values, and body temperature increased to $0.2^{\circ} \mathrm{C}$ above baseline. When 1.3 or $\geq 4.5 \mathrm{~L} /$ min was applied, respiration rate was lower than the control and decreased relative to baseline, and body temperature stayed below baseline for at least $30 \mathrm{~min}$ after treatment ended. The treatment that best bal-
\end{abstract}

Received February 5, 2015.

Accepted June 16, 2015.

${ }^{1}$ Corresponding author: cbtucker@ucdavis.edu anced cooling effectiveness against water usage was 1.3 $\mathrm{L} /$ min: although $\geq 4.5 \mathrm{~L} / \mathrm{min}$ reduced respiration rate relative to baseline by 4 more breaths/min than $1.3 \mathrm{~L} /$ min did ( -13 vs. -9 breaths/min, respectively), each additional liter of water decreased this measure by only $\leq 0.1$ breaths $/ \min (\leq 1 \%$ of the total reduction achieved using $1.3 \mathrm{~L} / \mathrm{min}$ ). We found similar water efficiency patterns for skin temperature and the amount of time that body temperature remained below baseline after treatment ended. Thus, when using this intermittent spray schedule in a hot, dry climate, applying at least $1.3 \mathrm{~L} / \mathrm{min}$ improved cooling, but above this, additional physiological benefits were relatively minor.

Key words: heat load, sprinkler, soaker, water conservation

\section{INTRODUCTION}

Weather conditions such as high air temperature and exposure to solar radiation cause cattle to gain heat. Cows dissipate heat through evaporation by increasing respiration rate, panting, and, to a limited extent, sweating (Gebremedhin et al., 2008). However, when this is insufficient, the accumulated heat load can increase body temperature and decrease milk yield (Wheelock et al., 2010) and fertility (De Rensis and Scaramuzzi, 2003) and, in extreme cases, can result in mortality (Stull et al., 2008; Vitali et al., 2009).

To manage heat load, dairy producers provide shade, fans, spray cooling (sprinklers/soakers with large droplets, or misters with fine droplets), or a combination of these resources: $94 \%$ of US dairies use at least one of these types of heat abatement (USDA, 2010). Spray cooling, typically provided either in the holding pen or at the feed bunk, is common ( $62 \%$ of milking herds $\geq 500$ head; USDA, 2010) because it lowers body temperature and respiration rate (Valtorta and Gallardo, 2004; Kendall et al., 2007; Chen et al., 2013) and improves feed intake and milk yield in hot conditions (Keister et al., 2002). Although spray cooling is 1 of 3 main uses of potable water, along with drinking water (at least 57 to 110 L/d per cow; Kume et al., 2010) and water 
used for milking (e.g., cleaning cows before milking, milking equipment, and the milking parlor, 170 to 734 L/d per cow; Meyer et al., 2006), the amount of water used for cooling varies widely among farms (e.g., 23 to 256 L/d per cow; G. Tresoldi, University of CaliforniaDavis; personal communication). Along with increasing global temperatures, decreasing precipitation or changes in precipitation patterns are predicted to limit water availability (Rosenstock et al., 2006). Therefore, the ability to reduce heat load in cattle while reducing water consumption is an important issue for US dairy production.

There is little evidence for how much water is needed to effectively cool cows. Spray reduces heat load through evaporation when the water is turned off, as well as by cooling the microclimate around the cow. Some heat may be dissipated through fluid convection when water drips from the body but this is associated with speculative concerns about mastitis (e.g., as suggested by Flamenbaum et al., 1986). To determine how much water is needed to cool via evaporation, Arkin et al. (1991) estimated the evaporative potential of a wet, excised hide $\left(\leq 0.23 \mathrm{~L} / \mathrm{m}^{2}\right)$, and heat transfer models have been created for different ambient conditions (Kimmel et al., 1991; Gebremedhin and $\mathrm{Wu}, 2002$ ). However, there has been little experimental validation on live cows, and comparing cooling effectiveness across studies is challenging, as some do not report how much water is used (Araki et al., 1985; Igono et al., 1987; Valtorta and Gallardo, 2004), or use variable units of measure: most commonly liters per minute (e.g., Chen et al., 2013) or liters per hour (e.g., Gallardo et al., 2005), but also cubic meters per hour (Flamenbaum et al., 1986), millimeters per centimeter squared per hour (Granzin, 2006), milliliters per meter squared per minute (Schütz et al., 2011), or millimeters per hour (Kendall et al., 2007). The only study to date that directly compared sprinkler flow rates (mounted over the freestalls and without unsprayed controls) found no differences in heat load when spraying $5.2,8.2$, or $11.7 \mathrm{~L} / \mathrm{min}$ in 1.5 min applications in a hot, humid climate (Means et al., 1992). It seems likely that effective cooling can be achieved with less water than these relatively high flow rates; in a subsequent study that applied $5.2 \mathrm{~L} / \mathrm{min}$, Montoya et al. (1995) calculated from runoff that only $15 \%$ of the spray applied evaporated directly from the cows.

In addition to the amount of water, spray droplet size may play a role in cooling. Some smaller droplets may evaporate before reaching cattle; although this may cool the microclimate, the resulting increase in relative humidity may also reduce the potential for water to evaporate from the cows. Small droplets can also ac- cumulate on the hair coat, which some have suggested may limit cooling effectiveness (Hahn, 1985; Flamenbaum et al., 1986) or even create an insulating barrier which traps heat (Armstrong, 1994; Mitlöhner et al., 2001). In contrast, larger droplets may be less likely to evaporate before reaching the cow and could better penetrate the hair coat to the skin, improving cooling effectiveness, but this has not been explicitly examined.

Our objective was to determine how sprinkler flow rate and droplet size influence physiological signs of heat load in a hot, dry climate and the efficiency of water usage. We predicted that measures of heat load would be lower for higher flow rates and larger droplet sizes (within a given flow rate).

\section{MATERIALS AND METHODS}

\section{Animals and Housing}

The study was conducted during the summer (June to August 2011) at the University of California-Davis dairy facility, with all procedures approved by the Institutional Animal Care and Use Committee. Twenty lactating, pregnant Holstein-Friesian dairy cows were used, with average parity $1.5 \pm 0.5$, DIM $181 \pm 51$, daily milk yield $39 \pm 4 \mathrm{~kg}$, and BW $643 \pm 58 \mathrm{~kg}$ (mean $\pm \mathrm{SD}$ ).

Cows were tested in 2 consecutive cohorts (10 cows each) and acclimated to the home pen for at least 3 d before testing. This concrete-floored pen included a water trough (automatically refilled to $808 \mathrm{~L}$ ), 16 shaded, sand-bedded freestalls with 3 fans (36-DMCH, $5 \mathrm{~m}^{3} / \mathrm{s}$; Future Products Corp., Mosinee, WI), and an ad libitum TMR formulated to NRC (1989) requirements using the PC Dairy system (Bath and Strasser, 1990). The shaded feed bunk was fitted with 6 sprinkler nozzles (TF-VP7.5 Turbo FloodJet wide-angle flat spray tip, 4.9 L/min; Spraying Systems Co., Wheaton, IL) that delivered $1.5 \mathrm{~min}$ of continuous spray, followed by 13 or 5 min off (at air temperature $\geq 22.2$ or $29.4^{\circ} \mathrm{C}$, respectively). These sprinklers were turned on only between 2200 and $0700 \mathrm{~h}$, which was $6 \mathrm{~h}$ after to $6 \mathrm{~h}$ before the daily treatment period; this was done to ensure that body temperature results were due to the treatments imposed, because sprinklers can reduce body temperature for up to $6 \mathrm{~h}$ (i.e., after a 90-min treatment; Kendall et al., 2007).

\section{Treatments}

Treatments were administered in an area that was separated from the rest of the home pen with portable livestock fencing panels (Powder River, Provo, UT). 


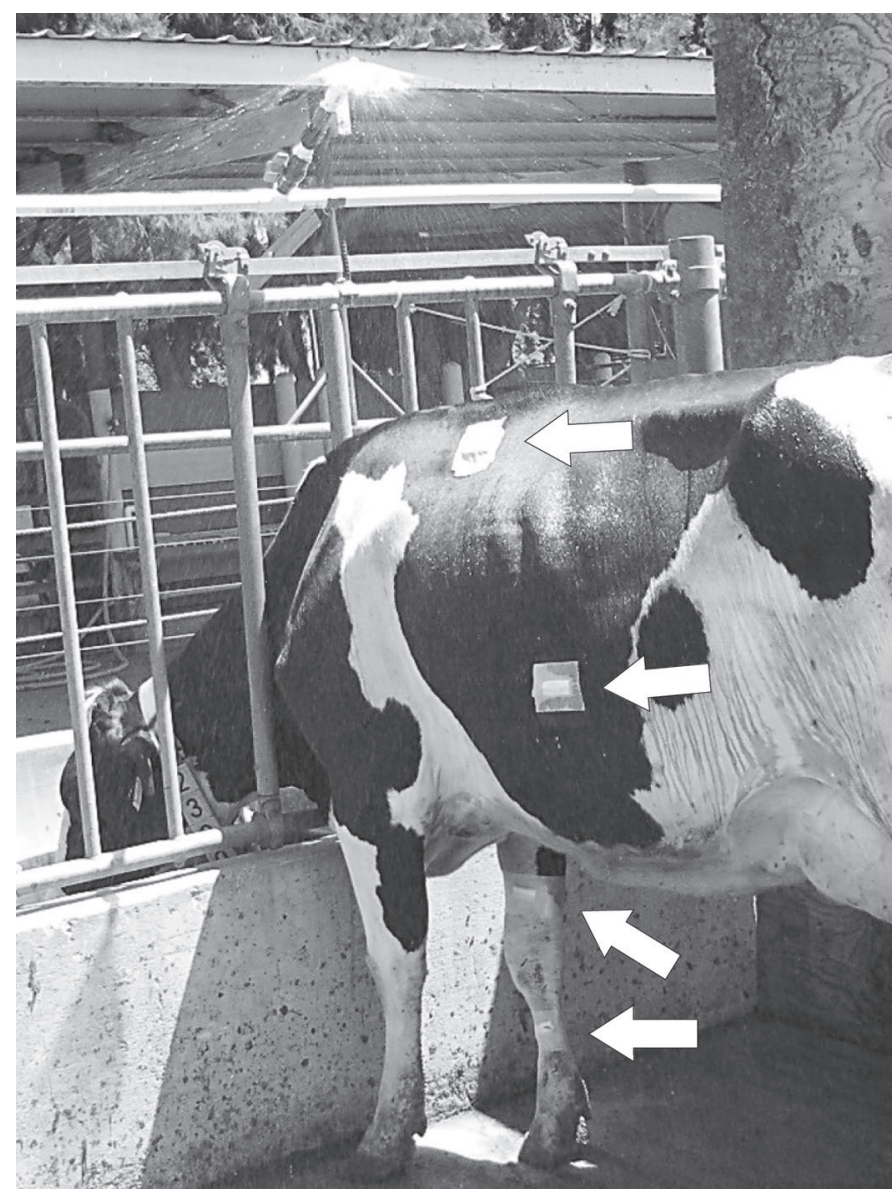

Figure 1. Skin surface temperature was recorded with data loggers on 4 parts of the body, indicated with arrows (from top to bottom: shoulder, side, upper leg, and lower leg) during $1 \mathrm{~h}$ of restraint under a soaker nozzle (e.g., $4.5 \mathrm{~L} / \mathrm{min}$, shown).
Cows were restrained for $1 \mathrm{~h} / \mathrm{d}$ in headlocks at an unshaded, clean feed bunk (35 $\mathrm{m}$ from the main shaded feed bunk) with a water line mounted overhead (Figure 1). Nozzles were angled such that the spray (from 1.9 $\mathrm{m}$ high) wetted the cows' backs. Treatments differed in water volume, which was manipulated as a function of flow rate, with spray application time held constant. One nozzle/cow, controlled manually with a ball valve, applied 4 spray applications of $3 \mathrm{~min}$ each, separated by $12 \mathrm{~min}$. This spray schedule has been used by others (Meyer et al., 2002) and we observed in pilot tests that when $1.3 \mathrm{~L} / \mathrm{min}$ was sprayed on 2 cows with dry hair coats, water began to run down their sides by around $3 \mathrm{~min}$. The total treatment time (48 min) was selected to mimic the length of an average feeding bout (e.g., 47 min; DeVries et al., 2003).

The study included 7 treatments: a control in which no water was applied, and 6 soaker nozzles (TKFloodJet wide angle flat spray tips; Spraying Systems Co.; Table 1) that delivered droplets considered at least Very Coarse (Doble et al., 1985; ASABE, 2009), comparable to "light to moderate rain" (Spraying Systems Co., 2013). All cows received all treatments 3 times each $(1$ treatment/d) in a crossover design, with order of exposure balanced across days (21 d total). Half of each cohort ( 5 cows) was tested either between 1300 and $1400 \mathrm{~h}$ or between 1445 and $1545 \mathrm{~h}$ daily, and the time and location of testing was consistent for each individual. Cows had visual contact with conspecifics through the headlocks but were separated by $2.4-\mathrm{m}-$ wide $\times 2.4$-m-tall plywood partitions to prevent spray drift between adjacent treatments. Each cow had $3 \mathrm{~m}$ of bunk space and a water bucket that was refilled as needed.

Table 1. Characteristics of 6 sprinkler nozzles (Spraying Systems Co., Wheaton, IL) that were compared; within each of the 3 flow rates, the nozzles differed in median droplet size

\begin{tabular}{|c|c|c|c|c|c|c|c|}
\hline $\begin{array}{l}\text { Nominal rated } \\
\text { flow rate }^{1} \\
(\mathrm{~L} / \mathrm{min})\end{array}$ & $\begin{array}{l}\text { Total water } \\
\text { volume }^{2}(\mathrm{~L})\end{array}$ & Nozzle ID & $\begin{array}{l}\text { Pressure }^{3} \\
{[\mathrm{kPa}(\mathrm{psi})]}\end{array}$ & $\begin{array}{c}\mathrm{VMD}^{4} \\
(\mu \mathrm{m})\end{array}$ & $\begin{array}{l}\text { Actual } \\
\text { flow rate } \\
(\mathrm{L} / \mathrm{min})\end{array}$ & $\begin{array}{c}\text { Flow rate sprayed } \\
\text { onto platform } \\
(\mathrm{L} / \mathrm{min})\end{array}$ & $\begin{array}{l}\text { Proportion } \\
\text { sprayed onto } \\
\text { platform }^{7}\end{array}$ \\
\hline 0.4 & 4.8 & TK-0.75 & $138(20)$ & 370 & $0.47(0.07)$ & $0.13(0.03)$ & 0.30 \\
\hline 1.3 & 15.6 & TK-2 & $207(30)$ & 450 & $1.32(0.01)$ & $0.46(0.03)$ & 0.35 \\
\hline 1.3 & 15.6 & TK-2.5 & $138(20)$ & 530 & $1.39(0.02)$ & $0.47(0.06)$ & 0.35 \\
\hline 4.9 & 58.8 & TK-7.5 & $207(30)$ & 660 & $4.62(0.05)$ & $1.53(0.05)$ & 0.33 \\
\hline
\end{tabular}

${ }^{1}$ Nominal water flow rate at a given operating pressure, as rated by nozzle manufacturer.

${ }^{2}$ Total water volume applied during a 1-h intermittent (four 3-min applications) spray treatment, based on nominal flow rate.

${ }^{3}$ Operating pressure of water at nozzle.

${ }^{4}$ Volume median diameter $=$ the droplet diameter at which half the spray volume comprises smaller droplets and half comprises larger droplets (Spray Analysis and Research Services, 1993, 1995).

${ }^{5}$ Mean (SD) water flow rate collected from each nozzle.

${ }^{6}$ Mean (SD) water flow rate collected from a plywood model of a cow's back to estimate the amount of water that would wet a cow.

${ }^{7}$ The proportion of water that sprayed onto the plywood model out of the total water sprayed. 


\section{Spray Measures}

Sprinkler water temperature was measured daily at each of the 5 headlocks with a digital thermometer (Fisher Inc., Pittsburgh, PA) both before (between 1210 and $1245 \mathrm{~h}$ ) and after (between 1540 and $1610 \mathrm{~h}$ ) testing.

At the conclusion of the study, the flow rate of all sprinkler treatments was measured at all 5 headlocks. Additionally, to estimate the amount of water that directly wetted the experimental cows, water was collected in foil pans affixed to a rectangular model of a cow's back that was constructed from plywood (Figure 2 ). Its dimensions were based on the average measurements of the first cohort of cows for width at shoulder, length from shoulder to tail head, and height at withers.

\section{Environmental Measures}

A portable weather station (WS-16; Novalynx Corp., Auburn, CA) onsite recorded air temperature $\left(\mathbf{T},{ }^{\circ} \mathrm{C}\right)$, black globe temperature $\left(\mathbf{B G T},{ }^{\circ} \mathrm{C}\right)$, solar radiation $\left(\mathbf{S R}, \mathrm{W} / \mathrm{m}^{2}\right)$, relative humidity $(\mathbf{R H}, \%)$, wind speed (WS, $\mathrm{m} / \mathrm{s})$, and rainfall $(\mathrm{mm})$ at 5 -min intervals. Additional measures of heat load were temperature-humidity index (THI) and heat load index (HLI), calculated according to the following equations from Kelly and Bond (1971) and Gaughan et al. (2008), respectively:

$$
\begin{gathered}
\text { THI }=(1.8 \times \mathrm{T}+32)-[(0.55-0.0055 \times \mathrm{RH}) \\
\times(1.8 \times \mathrm{T}-26)], \text { and } \\
\mathrm{HLI}=\text { if } \mathrm{BGT}>25[8.62+(0.38 \times \mathrm{RH}) \\
+(1.55 \times \mathrm{BGT})+\exp (-\mathrm{WS}+2.4)-(0.5 \times \mathrm{WS})], \\
\text { else }[10.66+(0.28 \times \mathrm{RH})+(1.3 \times \mathrm{BGT})-\mathrm{WS}] .
\end{gathered}
$$

\section{Physiological Measures}

Body temperature was recorded intravaginally at 1-min intervals using a data logger (Minilog12-TX, accuracy: $\pm 0.1^{\circ} \mathrm{C}$, resolution: $\pm 0.015^{\circ} \mathrm{C}, 1.6 \mathrm{~cm}$ in diameter $\times 7 \mathrm{~cm}$ long; Vemco Ltd., Bedford, NS, Canada) attached to a shortened, hormone-free controlled internal drug release insert (InterAg, Hamilton, New Zealand).

Respiration rate was recorded by counting 10 flank movements (converted to breaths/min to facilitate comparison with other studies) 8 times/d: 2 min before (min $-2,13,28$, and 43) and immediately after (min $4,19,34$, and 49) each of the 4 spray applications. Five observers recorded this measure over the course of the study; interobserver reliability for pairs ranged from 0.981 to 0.992 , as measured by Pearson correlation.
Skin temperature was recorded on 4 parts of the body (Figure 1): posterior to the left scapula (shoulder), between the second and third most posterior ribs on the left side (side), the inner right foreleg above the carpal joint (upper leg), and the inner right foreleg above the fetlock joint (lower leg), regardless of coat color. These areas were selected to compare parts of the body that were sprayed (shoulder and side) with those that remained dry (upper and lower leg). Additionally, we predicted that the temperature gradient among different body parts could provide insight into vasoconstriction in response to cooling (Finch, 1986; Osborn et al., 1992). Data loggers (Thermochron iButton DS1921H, accuracy: $\pm 1.0^{\circ} \mathrm{C}$, resolution: $\pm 0.125^{\circ} \mathrm{C}$; Embedded Data Systems, Lawrenceburg, KY) recording at 1-min intervals were affixed to $10-\times 10-\mathrm{cm}$ shaved areas of skin using surgical tape (3M Micropore, St. Paul, MN) before treatments were applied. Directly following each spray application, a single observer pressed $5-\times 5$-cm squares of water-sensitive paper impregnated with co-

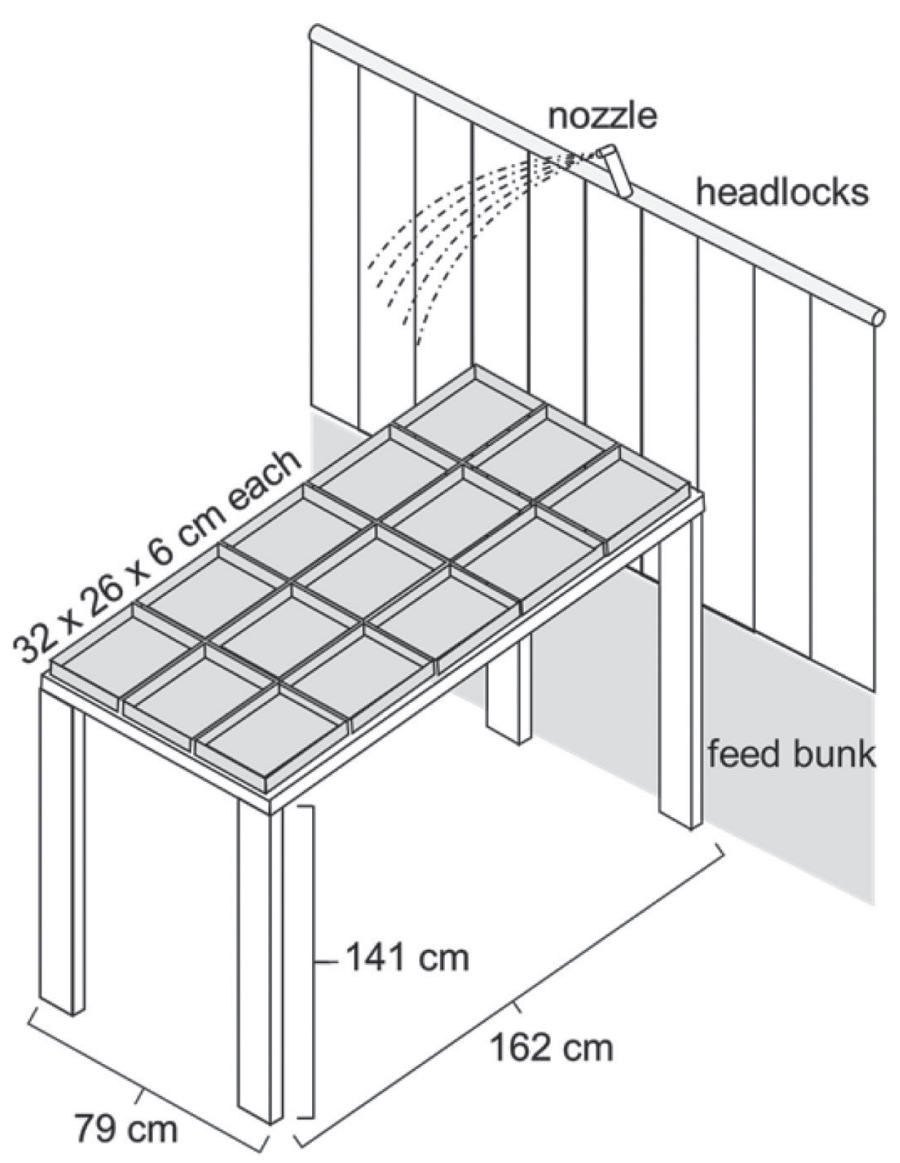

Figure 2. Configuration (not to scale) of a plywood model of a cow's back, upon which 15 foil pans were placed to collect sprayed water to calculate estimates of the amount that would wet a cow standing at the feed bunk. 
balt chloride (Science Kit, Tonawanda, NY) on the hair coat adjacent to each logger and assigned a wetness score $(0=$ completely dry; $1=<25 \%$ wet; $2=25-75 \%$ wet; $3=>75 \%$ wet). To capture vasoconstriction on the legs but avoid inadvertently measuring water temperature, any observations on the legs with wetness scores $\geq 1$ were excluded from analyses ( 5 and $23 \%$ of observations on the upper and lower leg, respectively).

\section{Statistical Analysis}

To evaluate the relationships among weather variables during testing and between each weather variable and sprinkler water temperature, PROC CORR (SAS Institute Inc., 2014) was used.

Analyses for all physiological measures were conducted using cow as the experimental unit; 1 cow was removed from the trial on d 4 due to an injury unrelated to the experiment, and her data were discarded (final $\mathrm{n}=19$ for respiration rate and skin temperature); additionally, data from 1 body temperature logger were lost (final $\mathrm{n}=18$ for this measure). For all physiological measures, differences among treatments were evaluated at baseline $(\min -2)$ and after the final spray application (min 49). To evaluate body temperature effects beyond min 49, both the time to return to baseline values and the time until the value for each sprinkler treatment converged with that of the contemporary control were compared among treatments; the latter comparison was conducted only for observations that had a simultaneously tested control. For each of these dependent variables, the model (PROC MIXED) included fixed terms for flow rate and droplet size nested within flow rate, along with weather during testing as a covariate; this analysis was repeated separately for each weather variable. In addition, for measurements taken after spray was applied, the interaction between flow rate and weather was also included (separately for each weather variable). For all models, random terms were included for cow and the interactions of cow with each fixed term to generate the appropriate error degrees of freedom. For skin temperature on the upper and lower leg, interactions with weather were not evaluated because sample size was reduced after discarding measurements with wetness scores $\geq 1$.

In addition, to determine when differences among treatments could first be detected for each physiological measure, analyses were conducted at min 4 for respiration rate, min 1 to 4 for skin temperature on all 4 body parts, and min 1 to 19 for body temperature. These times were selected by examining the measurements taken before and after each spray application (min 4, $13,19,28,34,43$, and 49) and identifying the earliest time that the standard error between any 2 treatments did not overlap. At each of these times, the model (PROC MIXED) included fixed terms for flow rate and droplet size nested within flow rate, and random terms for cow and the interactions of cow with each fixed term to generate the appropriate error degrees of freedom.

To determine whether physiological measures changed over the course of the 1-h treatment, baseline measurements were compared with those taken at the end of the treatments; these analyses were conducted separately for each flow rate. For each dependent variable, the model (PROC MIXED) included a fixed term for measurement time (min -2 or 49) and random terms for cow and cow $\times$ measurement time.

To control for the false discovery rate associated with conducting multiple comparisons, all $P$-values were adjusted using the Benjamini and Hochberg (1995) procedure in PROC MULTTEST, with the total number of hypotheses $(\mathrm{m})=250$. When overall corrected $P$-values were significant $(<0.05)$ or tended to be $(P<0.09)$, comparisons were then conducted between all pairs of flow rates using a Tukey-Kramer adjustment (Stoline, 1981).

\section{RESULTS}

\section{Spray and Environmental Characteristics}

Flow rates for each treatment are reported in Table 1. Sprinkler water temperature was $30.4 \pm 3.3^{\circ} \mathrm{C}$ (mean $\pm \mathrm{SD})$, and increased in warmer weather $(\mathrm{T}: \mathrm{r}=0.850$; THI: $\mathrm{r}=0.805 ;$ HLI: $\mathrm{r}=0.442 ;$ BGT: $\mathrm{r}=0.777 ; P$ $<0.001)$. Weather conditions for 24 -h and treatment periods are summarized in Table 2 . Rainfall was $0 \mathrm{~mm}$ throughout the study. Warmer days were less humid ( $\mathrm{T}: \mathrm{r}=-0.858$; THI: $\mathrm{r}=-0.753$; HLI: $\mathrm{r}=-0.471$; BGT: $\mathrm{r}=-0.788 ; P<0.001)$ and less windy $(\mathrm{T}: \mathrm{r}=$ -0.328 ; THI: $\mathrm{r}=-0.330$; HLI: $\mathrm{r}=-0.819$; BGT: $\mathrm{r}=$ $-0.539 ; P \leq 0.002)$.

\section{Body Temperature}

Droplet size did not affect body temperature (convergence with contemporary control: $F_{3,41}=0.9, P=$ 0.678; all other comparisons: $\left.F_{3,51} \leq 0.4, P \geq 0.919\right)$. Baseline body temperature $\left(39.2 \pm 0.6^{\circ} \mathrm{C}\right.$, mean $\left.\pm \mathrm{SD}\right)$ was the same for all flow rates $\left(F_{3,51}=0.7, P=0.721\right)$ and increased when the weather was warmer (T, THI, HLI, BGT: $F_{1,17} \geq 175.9, P<0.001$; Table 3$)$, sunnier (SR: $F_{1,17}=7.6, P=0.029$ ), or less humid or windy (RH, WS: $\left.F_{1,17} \geq 39.8, P<0.001\right)$.

Body temperature tended to differ among flow rates at min $11\left(F_{3,51}=2.9, P=0.087\right)$, with significant 
Table 2. Summary of daily weather conditions on experimental days in June to August 2011

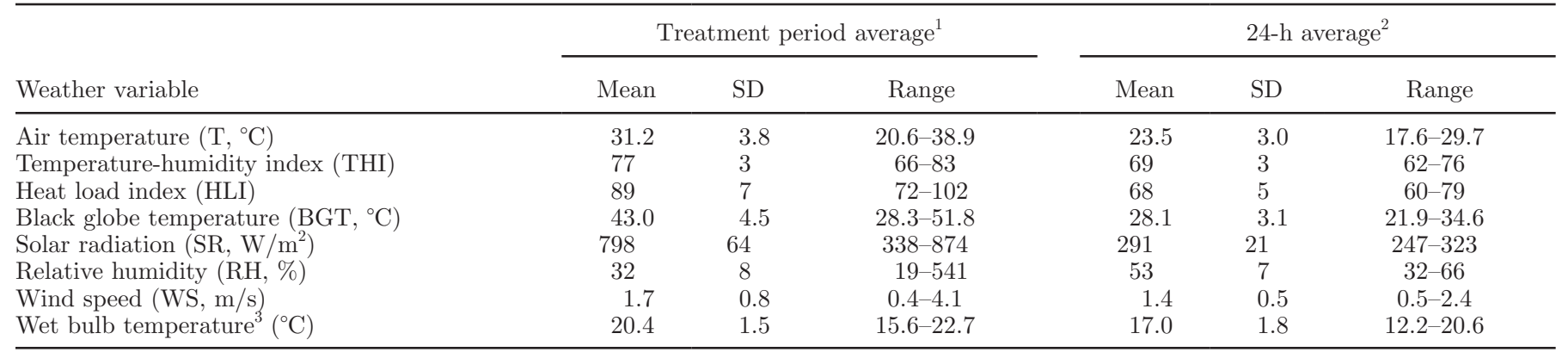

${ }^{1}$ Means, SD, and range (minimum to maximum of mean daily values) are given for 1300 to $1400 \mathrm{~h}$ and 1445 to $1545 \mathrm{~h}$ daily.

${ }^{2}$ Means, SD, and range (minimum to maximum of mean daily values) are given for $24 \mathrm{~h}$.

${ }^{3}$ Data to calculate wet bulb temperature were collected from the University of California Campbell Tract weather station, $1.5 \mathrm{~km}$ away from the dairy facility, whereas all other measures were recorded using a portable weather station.

differences detected at min $13\left(F_{3,51}=3.6, P=0.020\right.$; Figure $3 \mathrm{~A}$ ), before the second spray application. This measure also differed among flow rates at min $49\left(F_{3,51}\right.$ $=21.7, P<0.001)$. At this time, body temperature increased when conditions were warmer (T, THI, HLI, BGT: $F_{1,17} \geq 318.2, P<0.001$; Table 3 ) or less humid or windy (RH, WS: $F_{1,17} \geq 101.9, P<0.001$ ), regardless of flow rate (no weather $\times$ flow rate interactions: $\left.F_{3,51} \leq 2.2, P \geq 0.178\right) ;$ SR had no effect $\left(F_{1,17}=2.2\right.$, $P=0.287$ ). Relative to baseline, body temperature increased by at least $0.2^{\circ} \mathrm{C}$ during treatment when $0.4 \mathrm{~L} / \mathrm{min}$ or no water was applied $\left(F_{1,17} \geq 16.3, P \leq\right.$ 0.003; Figure $4 \mathrm{~A})$, but was maintained within $\pm 0.1^{\circ} \mathrm{C}$ of baseline when $\geq 1.3 \mathrm{~L} / \mathrm{min}$ was used $\left(F_{1,17} \leq 1.8, P\right.$ $\geq 0.348$ ).

After the sprinkler treatments stopped (min 49), body temperature decreased relative to baseline values when higher flow rates were used $\left(F_{3,51}=9.3, P<\right.$ 0.001; Figure 5): 1.3 and $\geq 4.5 \mathrm{~L} / \mathrm{min}$ kept this measure below baseline for 32 and $47 \mathrm{~min}$, respectively ( $\mathrm{SE}=$ $7.8 \mathrm{~min})$, which tended to be longer than with the other treatments $(0.4$ and $0 \mathrm{~L} / \mathrm{min}: 8 \pm 7.8$ and $0 \pm 10.0 \mathrm{~min}$ respectively, mean $\pm \mathrm{SE})$. Wind extended the duration: for flow rates $\geq 1.3 \mathrm{~L} / \mathrm{min}$, each $1 \mathrm{~m} / \mathrm{s}$ increase in $\mathrm{WS}$ kept body temperature below baseline for at least 27 min longer $\left(\mathrm{WS} \times\right.$ flow rate interaction: $F_{3,51}=3.7$,

Table 3. Physiological responses to heat load (body temperature, respiration rate, and skin surface temperature measured on 4 parts of the body) before and after $^{1}$ a 1 -h treatment, depending on weather conditions (all $P<0.05$, except where noted as NS) ${ }^{2}$

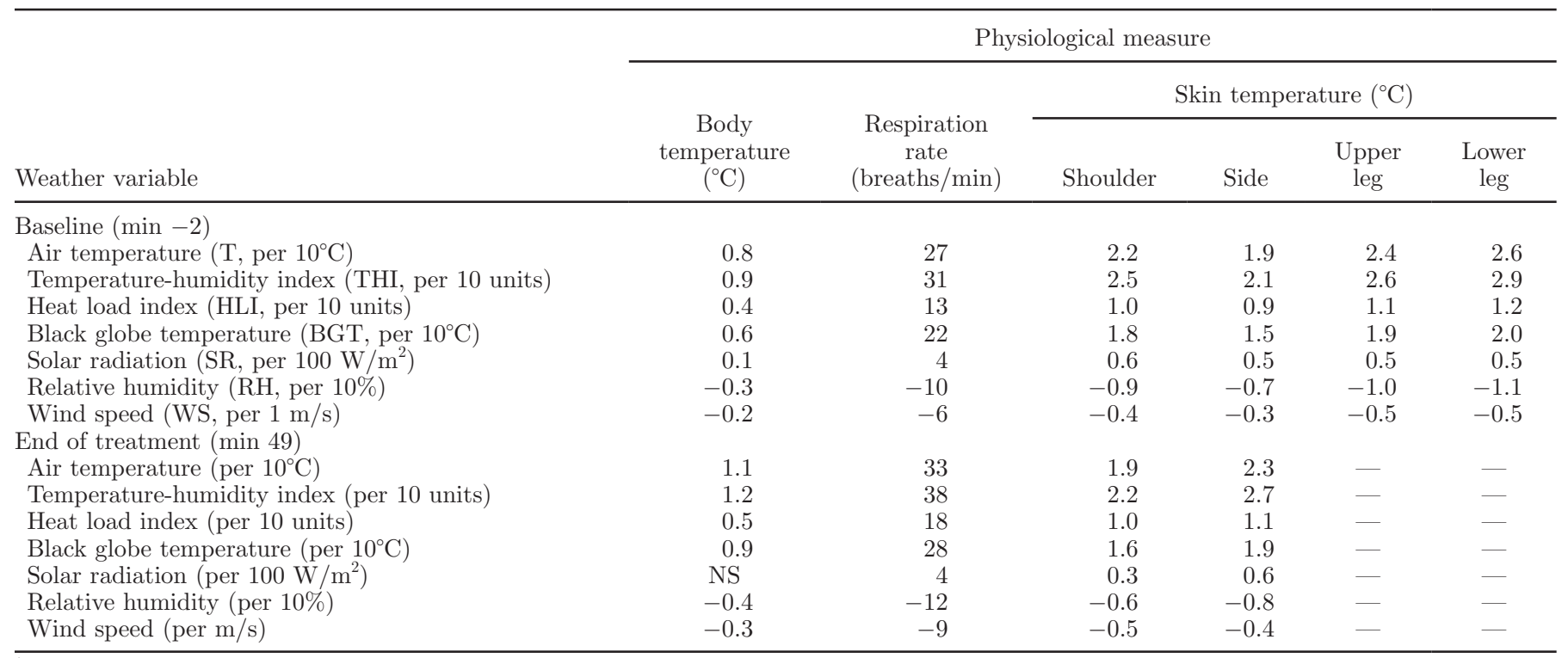

${ }^{1}$ For the end of treatment, no analysis was performed for the upper and lower leg, as measurements where the skin was wet were excluded.

${ }^{2}$ Reported values are slopes (i.e., change in each physiological measure per unit increase of each weather variable). 
(A)

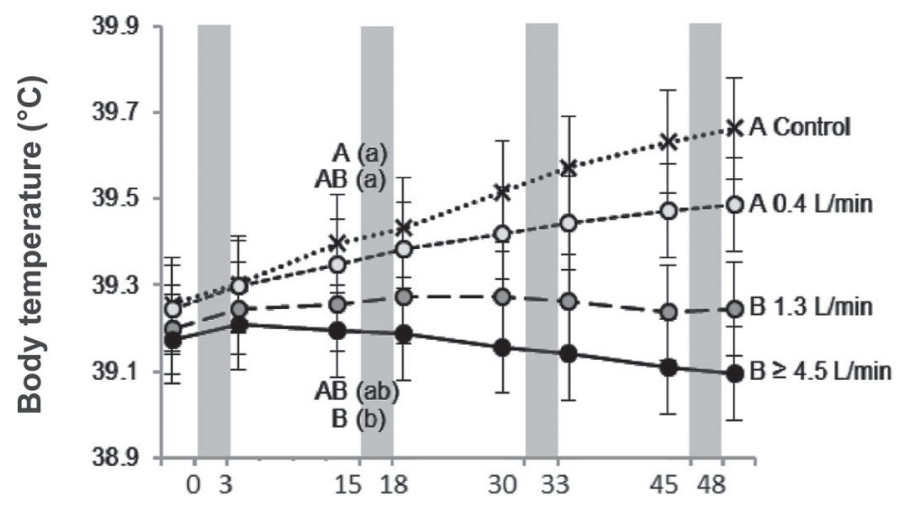

(B)

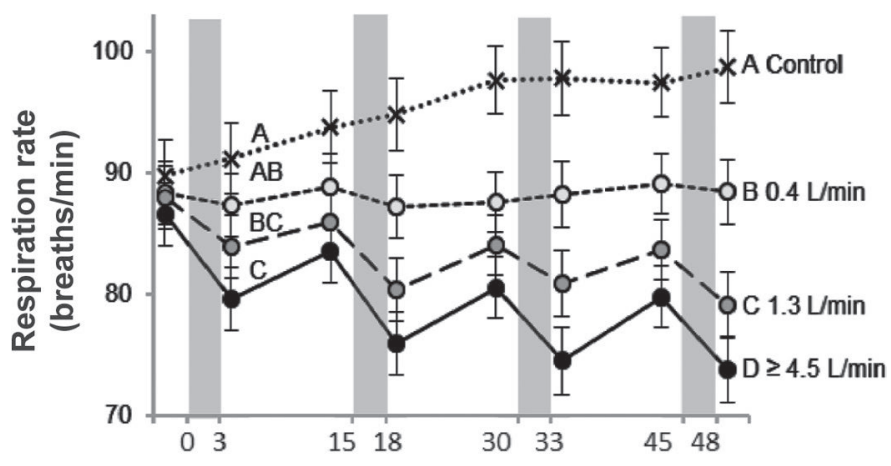

Time relative to start of treatment $(\mathrm{min})$

Figure 3. Mean (A) body temperature ( $\mathrm{n}=18$ cows) and (B) respiration rate $(\mathrm{n}=19$ cows) in response to 3-min spray (shaded areas) applied 4 times, separated by $12 \mathrm{~min}$. Measurements are shown before and after each spray application, when respiration rate was recorded. Error bars represent SE. Differences in body temperature and respiration rate among flow rates were detected at min 13 and min 4 after start, respectively. Letters indicate differences in physiological measures among flow rates (uppercase letters $=P<0.05$; lowercase letters in parentheses $=P<0.09$ ).

$P=0.037 ;$ all other weather variables: $F_{3,51} \leq 2.0, P$ $\geq 0.220$ ). Regardless of flow rate, body temperature remained below baseline for less time when HLI was higher $\left(F_{1,17}=9.9, P=0.014\right.$; all other weather variables: $\left.F_{1,17} \leq 3.4, P \geq 0.159\right)$.

Body temperature for all flow rates converged with the contemporary control between $2 \mathrm{~h} 6 \mathrm{~min}$ and $2 \mathrm{~h}$ $18 \mathrm{~min}$ after the end of treatment (no differences overall: $\left.F_{2,33}=0.1, P=0.998\right)$. Treatments took longer to converge when the weather was warmer (T, HLI, BGT: $F_{1,17} \geq 8.0, P \leq 0.027$; THI: $\left.F_{1,17}=5.7, P=0.060\right)$ or less humid or windy (RH, WS: $F_{1,17} \geq 13.8, P \leq 0.005$ ), regardless of flow rate (no weather $\times$ flow rate interactions: $\left.F_{2,30} \leq 0.9, P \geq 0.650\right)$; SR had no effect $\left(F_{1,17}=\right.$ $1.2, P=0.480)$.
(A)

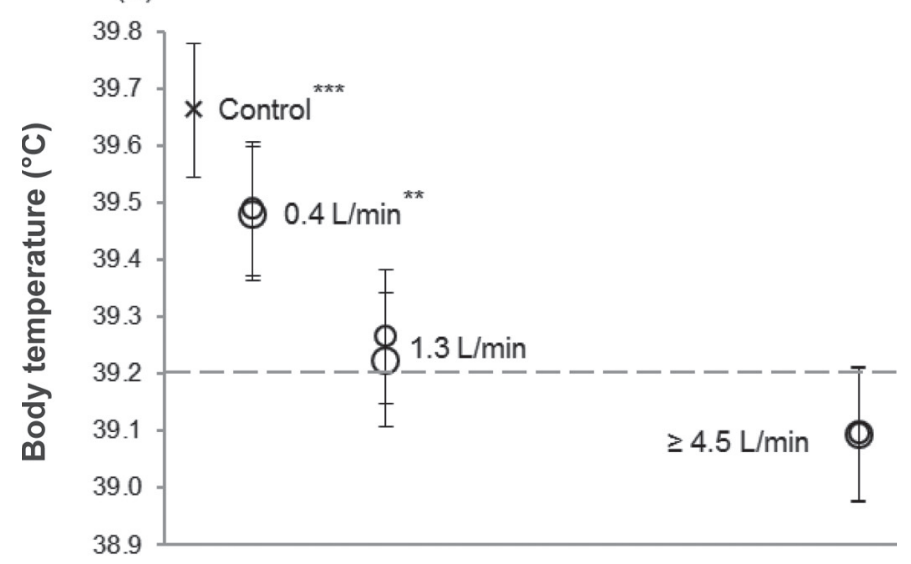

(B)

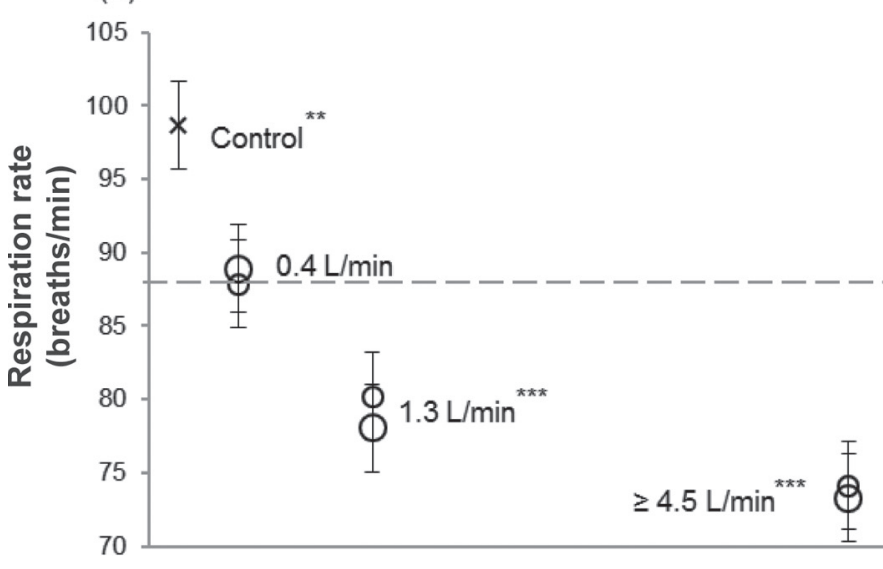

Flow rate (L/min)

Figure 4. Mean (A) body temperature $(\mathrm{n}=18$ cows $)$ and $(\mathrm{B})$ respiration rate $(\mathrm{n}=19$ cows $)$ after a 1 -h sprinkler treatment. Within each flow rate, droplet size did not affect physiological measures of heat load; symbol size indicates which nozzle (within each pair that shared a flow rate) delivered relatively larger or smaller droplets. Error bars represent SE. Mean baseline values $(---)$ are shown; measurements at the end of treatment that differed from baseline are indicated: ${ }^{* *} P<0.01,{ }^{* * *} P<0.001$.

\section{Respiration Rate}

Droplet size did not affect respiration rate $\left(F_{3,54} \leq\right.$ $0.3, P \geq 0.978)$. Baseline respiration rate $(88 \pm 16.5$ breaths $/$ min, mean $\pm \mathrm{SD}$ ) was the same among flow rates $\left(F_{3,54}=0.8, P=0.703\right)$ and increased when the weather was warmer (T, THI, HLI, BGT: $F_{1,18} \geq 242.3$, $P<0.001$; Table 3), sunnier (SR: $F_{1,18}=10.1, P=$ 0.013 ), or less humid or windy (RH, WS: $F_{1,18} \geq 35.8$, $P<0.001)$.

Respiration rate differed among flow rates immediately following the first spray application at min $4\left(F_{3,54}\right.$ $=9.9, P<0.001 ;$ Figure $3 \mathrm{~B})$, as well as at min $49\left(F_{3,54}\right.$ $=44.2, P<0.001)$. At the end of treatment $(\min 49)$, 


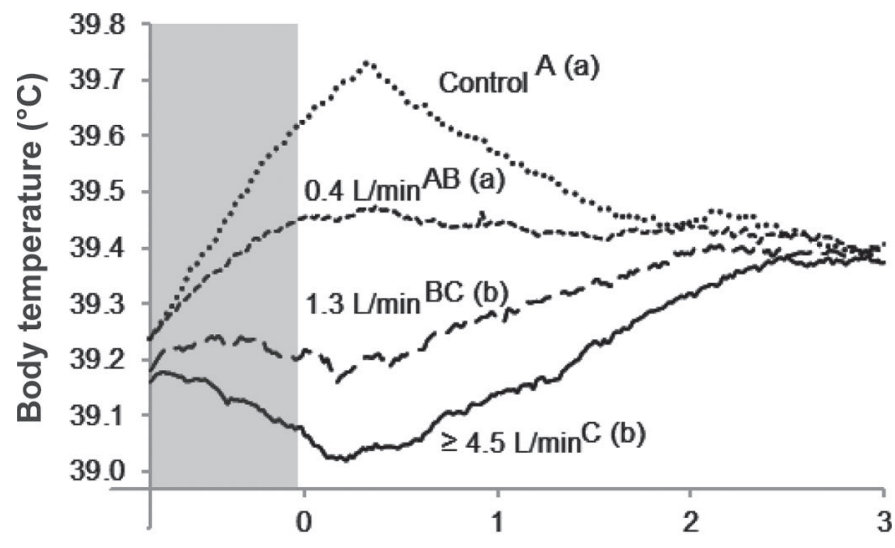

Time relative to end of treatment $(\mathrm{h})$

Figure 5. Mean body temperature during (shaded area) and after a $1 \mathrm{~h}$ sprinkler treatment. Letters indicate differences among flow rates in how long body temperature remained below baseline following treatment (uppercase letters $=P<0.05$; lowercase letters in parentheses $=P<0.09)$

this measure increased when conditions were warmer (T, THI, HLI, BGT: $F_{1.18} \geq 527.7, P<0.001$; Table 3 ) or less humid or windy (RH, WS: $F_{1,18} \geq 92.7, P<$ 0.001 ), and tended to show the same pattern when it was sunnier (SR: $\left.F_{1,18}=5.3, P=0.067\right)$, regardless of flow rate (no weather $\times$ flow rate interactions: $F_{3,54} \leq$ 1.3, $P \geq 0.461)$. During the 1 -h treatment, respiration rate increased by 9 breaths/min above baseline when cows had no sprinklers $\left(F_{1,18}=11.4, P=0.009\right.$; Figure $4 \mathrm{~B})$, was maintained at baseline values when $0.4 \mathrm{~L} /$ min was used $\left(F_{1,18}=0.0, P=0.998\right)$, and decreased by 9 and 13 breaths $/$ min when 1.3 and $\geq 4.5 \mathrm{~L} / \mathrm{min}$, respectively, were applied $\left(F_{1,18} \geq 23.5, P<0.001\right)$.

\section{Skin Temperature}

Droplet size did not affect skin temperature on any body part $\left(F_{3,54} \leq 1.2, P \geq 0.531\right)$. Baseline skin temperature (shoulder: $38.5 \pm 1.1^{\circ} \mathrm{C}$; side: $37.3 \pm 0.8^{\circ} \mathrm{C}$; upper leg: $36.8 \pm 1.0^{\circ} \mathrm{C}$; lower leg: $36.4 \pm 1.1^{\circ} \mathrm{C}$; mean $\pm \mathrm{SD})$ was the same regardless of flow rate $\left(F_{3,54} \leq\right.$ $1.4 ; P \geq 0.421)$ and increased for all body parts when the weather was warmer (T, THI, HLI, BGT: $F_{1,18} \geq$ 305.2, $P<0.001$; Table 3), sunnier (SR: $F_{1,18} \geq 23.9$, $P<0.001$ ), or less humid or windy (RH, WS: $F_{1,18} \geq$ $36.7, P<0.001)$.

Skin temperature differed among flow rates during the first spray application for all body parts (Figure 6 ): on the side of the body, this measure tended to differ among treatments at min $1\left(F_{3,54}=3.2, P=\right.$ $0.064)$, with significant differences detected at min 2 $\left(F_{3,54}=14.5, P<0.001\right)$ for both this body part and the shoulder $\left(F_{3,54}=16.0, P<0.001\right)$, and at min 3 for both the upper $\left(F_{3,54}=4.4, P=0.019\right)$ and lower $\left(F_{3,49}\right.$ $=3.9, P=0.033)$ leg. Skin temperature also differed among flow rates at the end of treatment (min 49) for all body parts $\left(F_{3,54} \geq 16.3, P<0.001\right)$. At that time, values on both the shoulder and side increased when the weather was warmer (T, THI, HLI, BGT: $F_{1,18} \geq$ 237.7, $P<0.001$; Table 3), sunnier (SR: $F_{1,18} \geq 8.8, P$ $\leq 0.020$ ), or less humid or windy (RH, WS: $F_{1,18} \geq 30.9$, $P<0.001$ regardless of flow rate (no weather $\times$ flow rate interactions: $F_{3,54} \leq 2.5, P \geq 0.140$ ).

Over the course of the 1-h treatment, skin temperature on all 4 body parts increased relative to baseline by 0.4 to $0.5^{\circ} \mathrm{C}$ when cows were not sprayed $\left(F_{1,18} \geq\right.$ $6.0, P \leq 0.045$; Figure 7 ). On parts of the body that were sprayed directly, all flow rates reduced skin temperature relative to baseline: by at least $2.4^{\circ} \mathrm{C}$ on the shoulder $\left(F_{1.18} \geq 251.3, P<0.001\right)$ and $1.3^{\circ} \mathrm{C}$ on the side $\left(F_{1,18} \geq 100.0, P<0.001\right)$. For the upper leg, which remained dry, $\geq 4.5 \mathrm{~L} /$ min reduced skin temperature to $0.5^{\circ} \mathrm{C}$ below baseline $\left(F_{1,18}=12.5, P=0.006\right)$, whereas 0.4 and $1.3 \mathrm{~L} / \mathrm{min}$ maintained skin temperature on this body part within 0.1 and $-0.2^{\circ} \mathrm{C}$ of baseline, respectively $\left(F_{1,18} \leq 3.1, P \geq 0.178\right)$. For the lower leg, which also remained dry, flow rates $\geq 1.3 \mathrm{~L} /$ min reduced skin temperature by at least $0.5^{\circ} \mathrm{C}$ below baseline $\left(F_{1,18} \geq\right.$ 7.6, $P \leq 0.029)$, whereas $0.4 \mathrm{~L} / \mathrm{min}$ maintained skin temperature within $0.1^{\circ} \mathrm{C}$ of baseline values $\left(F_{1.18}=0.3\right.$, $P=0.773)$.

\section{DISCUSSION}

During or following a single 3-min spray application, body temperature, respiration rate, and skin temperature were lower when $\geq 4.5 \mathrm{~L} / \mathrm{min}$ was applied relative to an unsprayed control. For all flow rates, we observed lower respiration rate and skin temperature on the directly sprayed body parts by the end of the 1-h intermittent ( $3 \mathrm{~min}$ on, 12 min off) sprinkler treatment compared with the control treatment. However, only sprinklers delivering $\geq 1.3 \mathrm{~L} / \mathrm{min}$ resulted in lower body temperature and skin temperature on the legs compared with the control treatment, reduced respiration rate relative to baseline values, and kept body temperature below baseline for at least 30 min after treatment ended.

\section{Physiological Response to Ambient Conditions}

All physiological measures increased when ambient conditions were warmer, sunnier, or less humid or windy - a pattern that is observed across the literature. For example, with each $7^{\circ} \mathrm{C}$ increase in air temperature in our study, baseline respiration rate and body temperature increased by about 19 breaths/min and $0.6^{\circ} \mathrm{C}$, 
.......... Control

(A) Shoulder

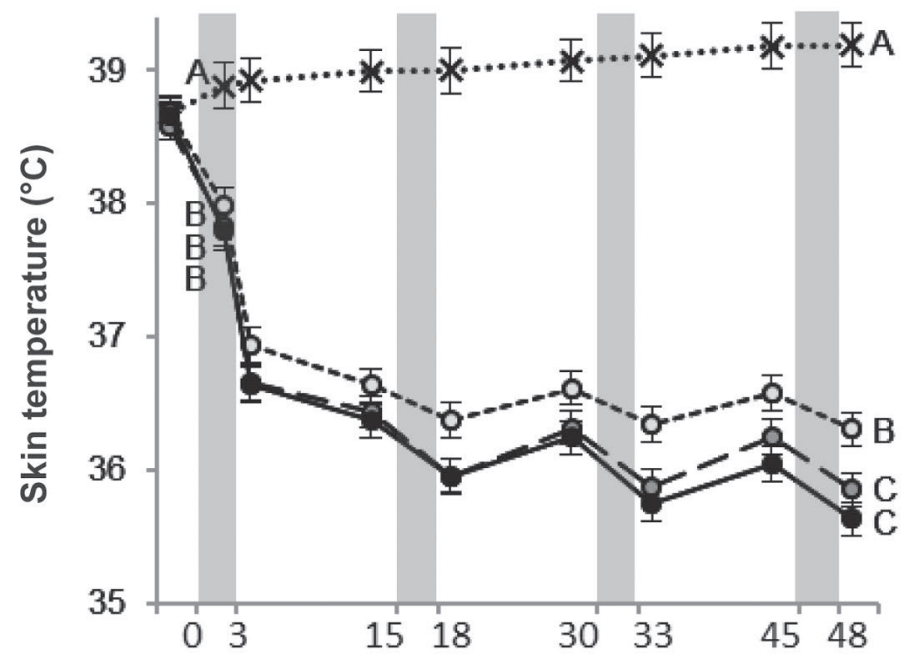

(C) Upper leg

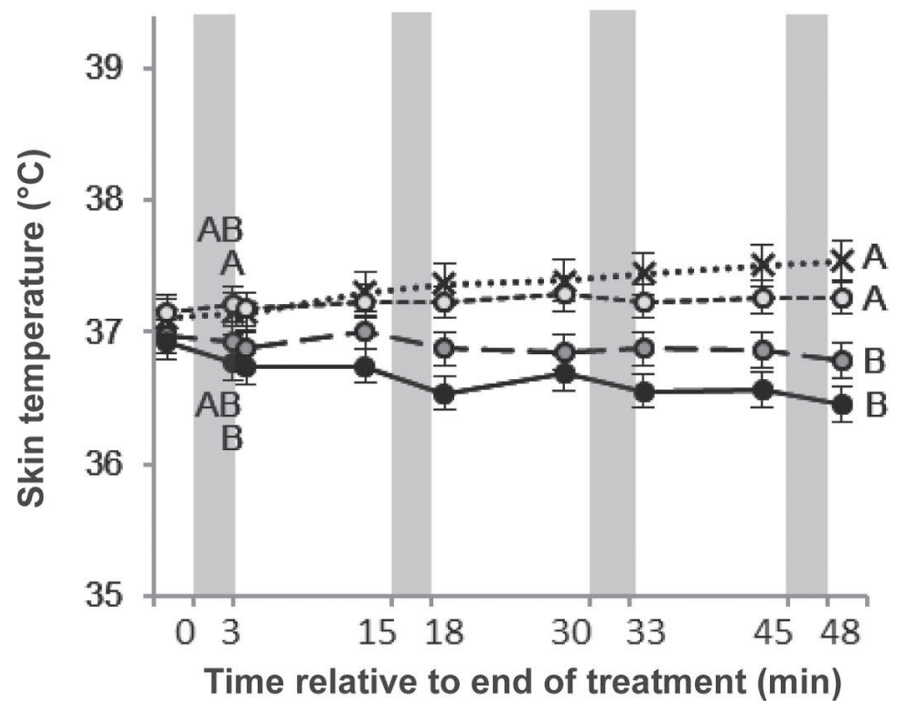

$-0-1.3 \mathrm{~L} / \mathrm{min}$

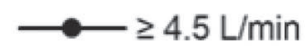

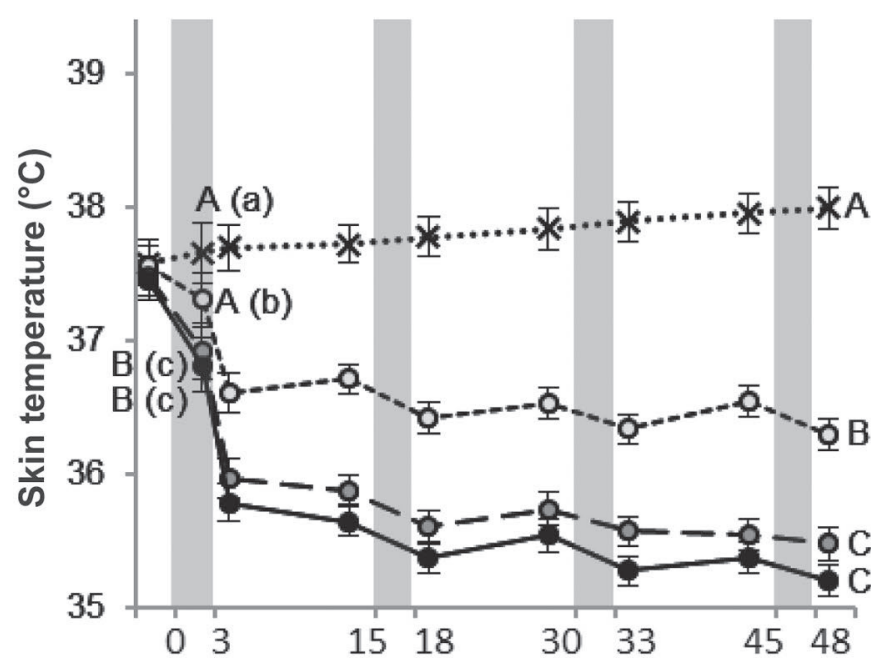

(D) Lower leg

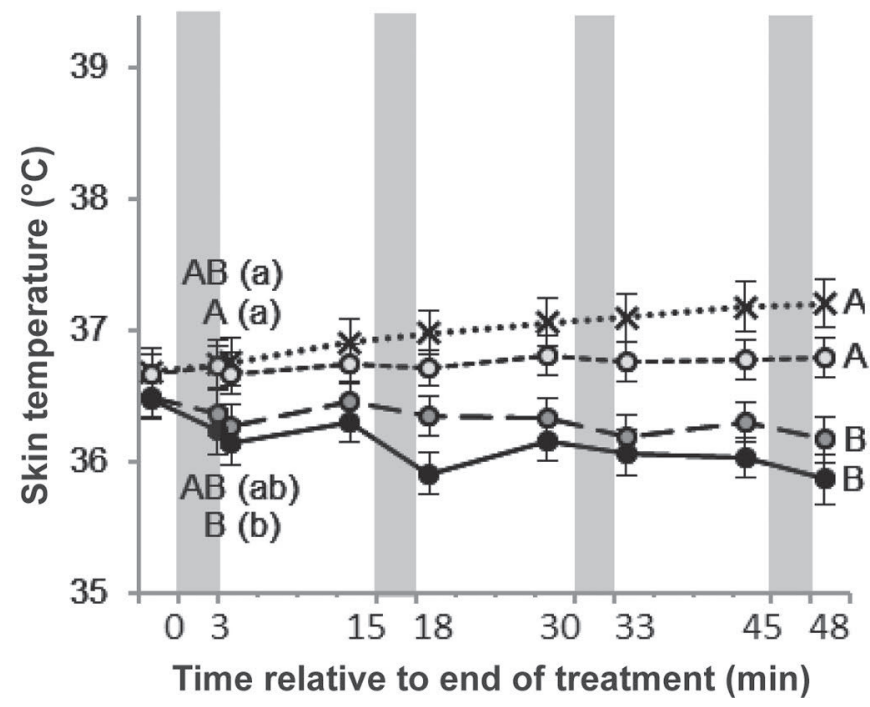

Figure 6. Mean skin surface temperature on the (A) shoulder, (B) side, (C) upper, and (D) lower leg in response to 3-min spray (shaded areas) applied 4 times, separated by 12 min. Measurements are shown before and after each spray application, to correspond with when respiration rate was recorded. Error bars represent SE $(n=19$ cows). Differences in skin temperature among flow rates were detected during the first spray application: at min 2 for the shoulder and side, and min 3 for the upper and lower leg. Letters indicate differences in skin temperature among flow rates (uppercase letters $=P<0.05$; lowercase letters in parentheses $=P<0.09$ ).

respectively. The relationships are similar when comparing across experiments: our average air temperature during testing was at least $7^{\circ} \mathrm{C}$ higher than that in some other studies (Kendall et al., 2007; Schütz et al., 2011), and our baseline respiration rate and body temperature were also at least 16 breaths/min and $0.4^{\circ} \mathrm{C}$ higher, respectively. We also found a relationship with shoulder skin temperature that replicated the findings of Schütz et al. (2011): for each $100 \mathrm{~W} / \mathrm{m}^{2}$ increase in solar radiation, skin temperature increased by 0.6 and $0.4^{\circ} \mathrm{C}$, respectively (note that the authors reported $0.004^{\circ} \mathrm{C}$, but this was in error according to K. Schütz). Ambient conditions are also associated with the accumulation of heat load over time: after $1 \mathrm{~h}$ without cooling in our study, respiration rate in the control treatment increased by 11 breaths/min and body temperature 


\section{(A) Shoulder}

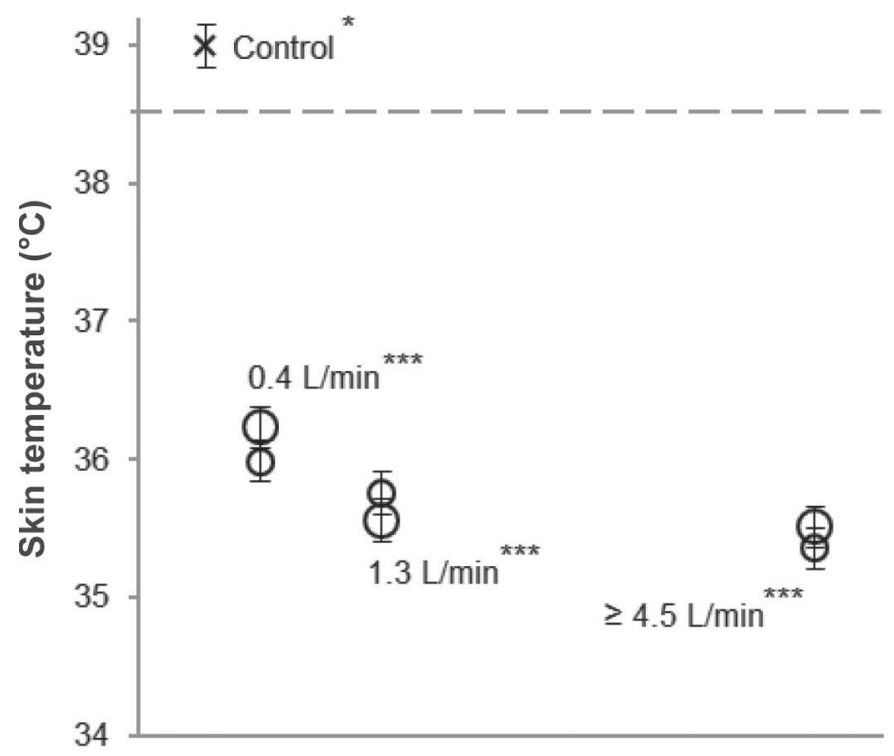

(C) Upper leg

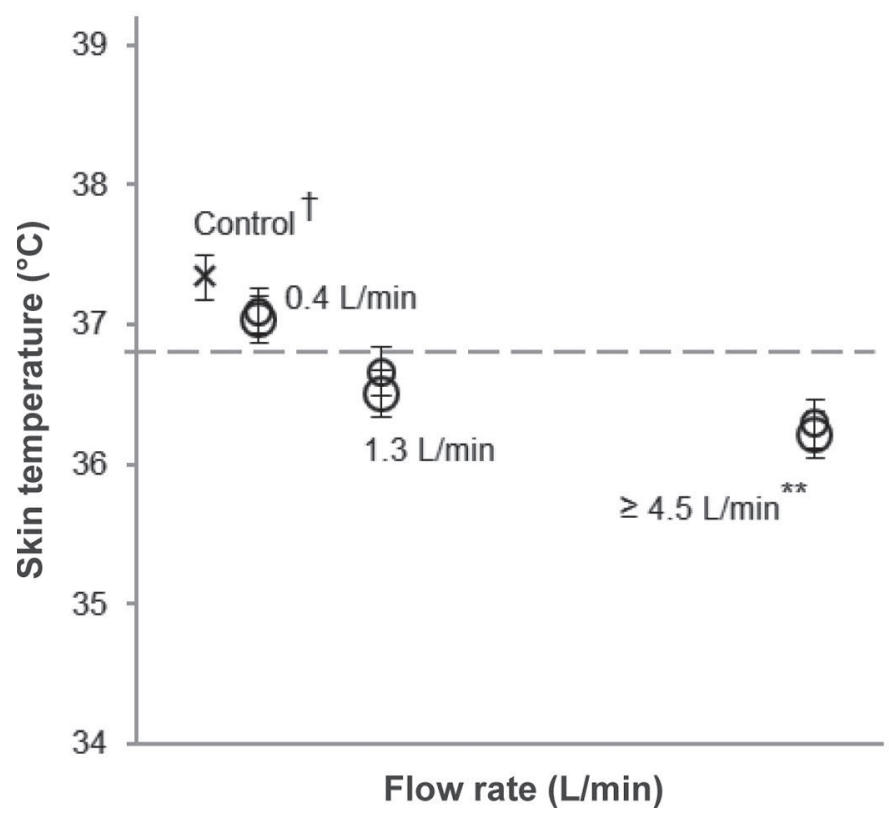

(B) Side

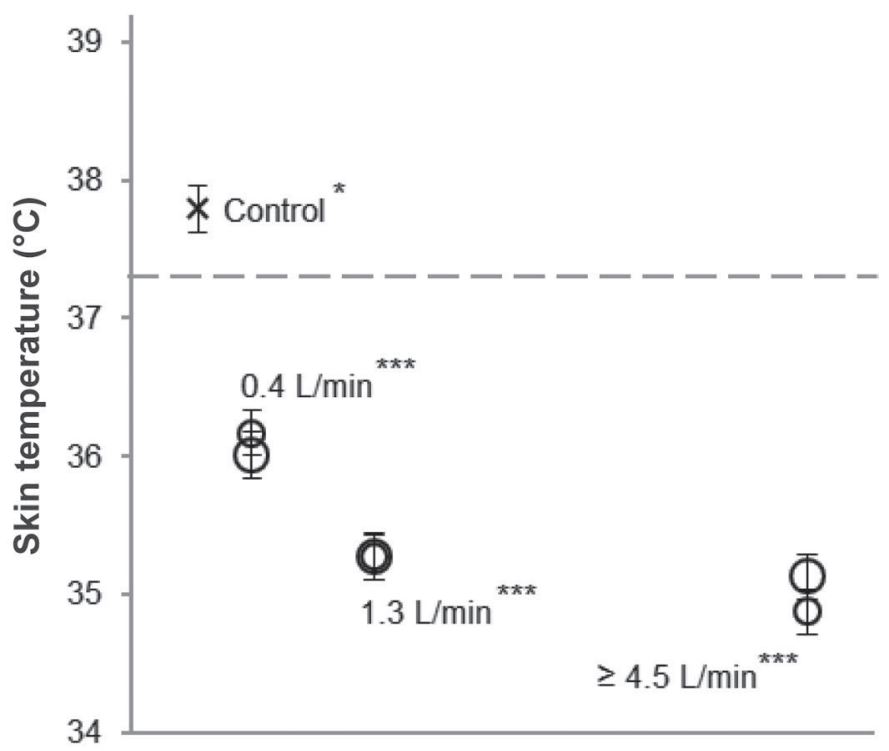

(D) Lower leg

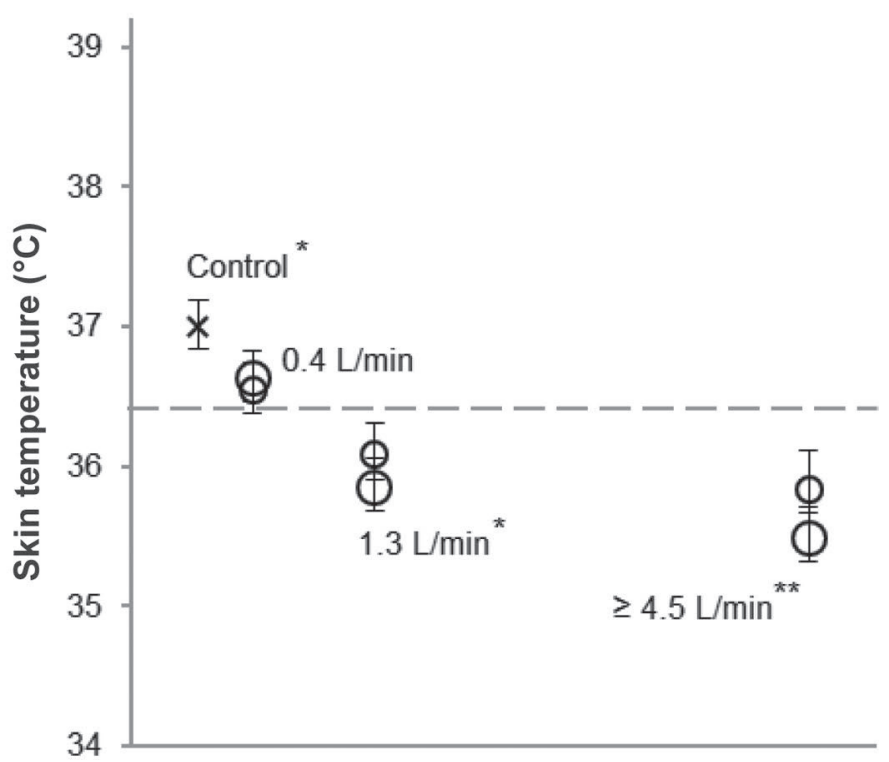

Flow rate (L/min)

Figure 7. Mean skin surface temperature on the (A) shoulder and (B) side, which were sprayed directly, and the (C) upper and (D) lower leg, which remained dry, after a 1-h sprinkler treatment. Within each flow rate, droplet size did not affect cooling; symbol size indicates which nozzle (within each pair that shared a flow rate) delivered relatively larger or smaller droplets. Error bars represent SE (n = 19 cows). Mean baseline values $(---)$ are shown for each body part; measurements at the end of treatment that differed from baseline are indicated: $\nmid P<0.09$, ${ }^{*} P<0.05,{ }^{* *} P<0.01,{ }^{* * *} P<0.001$.

increased by $0.5^{\circ} \mathrm{C}$ relative to baseline, whereas these measures increased by only 6 breaths $/ \mathrm{min}$ and $0.3^{\circ} \mathrm{C}$ above baseline, respectively, when unsprayed cows were tested for 90 min in cooler conditions (Kendall et al., 2007).

\section{Timing of Physiological Responses to Spray}

The timing of when each physiological variable first responded to spray application depended on both the measure and sprinkler flow rate. For skin temperature, 
changes began to occur during the first 3-min spray application: at min 2, all sprinkler flow rates resulted in lower skin temperature relative to the control on the shoulder, and tended to on the side of the body as well; at $\min 3, \geq 4.5 \mathrm{~L} / \mathrm{min}$ resulted in lower skin temperature than $0.4 \mathrm{~L} / \mathrm{min}$ on the upper leg, and tended to result in lower values than the control on the lower leg. Ours is the first study to evaluate changes in skin temperature while spray is being applied; others have found this measure to be lower relative to controls after 10 min of spray (Schütz et al., 2011). We also found that immediately following the first spray application, flow rates $\geq 1.3 / \mathrm{min}$ resulted in lower respiration rates relative to the control. Ours is the first study to find changes in this measure after 3 min of spray; others have found it to be lower compared with controls at the end of 90- and 10-min spray applications, respectively (Kendall et al., 2007; Schütz et al., 2011), or after a 20- to 30-min premilking sprinkler treatment (Valtorta and Gallardo, 2004). Finally, we found that body temperature changed before the second spray application: at $\min 13, \geq 4.5 \mathrm{~L} / \mathrm{min}$ resulted in lower values than the control (and tended to relative to $0.4 \mathrm{~L} / \mathrm{min}$ as well). Brown-Brandl et al. (2010) found similar timing: when beef heifers were sprayed for $\leq 30 \mathrm{~s}$ with a hose, body temperature was lower than that of controls after approximately $11 \mathrm{~min}$.

\section{Skin Temperature and Heat Flow in the Body}

The skin temperature patterns we observed were consistent with predicted heat flow in the body: baseline measurements were lower toward the extremities, decreasing by at least $0.5^{\circ} \mathrm{C}$ from the torso (shoulder and side) to the upper leg, and by another $0.4^{\circ} \mathrm{C}$ to the lower leg. Hernández-Rivera et al. (2011) likewise recorded lower skin temperature on body parts further from the core $\left(\leq 0.2^{\circ} \mathrm{C}\right.$ lower on the thurl vs. flank), but the opposite pattern has also been reported for the same locations (Avendaño-Reyes et al., 2012). Sun exposure may affect these measurements: in our study, skin temperature was higher on the shoulder, which received direct sunlight during treatment, compared with the side, which was typically shaded by the body.

At the end of the 1-h intermittent sprinkler treatment, all flow rates substantially lowered skin temperature on the shoulder and side relative to both baseline values and the control. When Schütz et al. (2011) recorded surface temperature on the shoulder, this measure was $4^{\circ} \mathrm{C}$ lower for sprayed cows than for controls, similar to the $\geq 2.9^{\circ} \mathrm{C}$ difference we found. On directly wetted body parts, it is possible that skin temperature measurements also reflect water temperature, which was, on average, $8^{\circ} \mathrm{C}$ and $10^{\circ} \mathrm{C}$ lower than baseline shoulder surface temperature in our study and that of Schütz et al. (2011), respectively.

On the leg, which remained dry, only the higher flow rates affected skin temperature: $\geq 1.3 \mathrm{~L} / \mathrm{min}$ resulted in lower values at the end of $1 \mathrm{~h}$ compared with the control, and $\geq 4.5 \mathrm{~L} / \mathrm{min}$ reduced this measure relative to baseline as well. Reduced skin temperature on the leg is consistent with vasoconstriction in response to cooling (Finch, 1986; Osborn et al., 1992), but it is also possible that this change reflected the cooler microclimate surrounding the cow, also associated with spray (Araki et al., 1985; Kendall et al., 2007; Chen et al., 2013).

Measuring skin temperature by affixing loggers directly onto shaved skin may have affected heat flow compared with other parts of the body that were covered by hair but not by a logger. Alternative techniques for measuring skin or surface temperature have other challenges: infrared guns (e.g., Hernández-Rivera et al., 2011; Schütz et al., 2011) and thermography (e.g., Osborn et al., 1992) are poorly suited for use in direct sunlight or on wet surfaces, cows kicked when a thermocouple probe (e.g., Legrand et al., 2011) was applied to the leg during pilot testing, and subdermal probes (used to assess wound healing in pigs; Cuttle et al., 2010) are more invasive. Rather than using skin temperature to indirectly assess vasodilation and constriction, noninvasive ultrasound has been used to measure blood flow more directly in both beef and dairy cattle (Bollwein et al., 2000; Kirch et al., 2008); this technique warrants further exploration for evaluating responses to heat-abatement strategies such as sprinklers.

\section{Body Temperature Beyond the End of Treatment}

We used 2 approaches to assess how sprinklers affected body temperature in the longer term: for each flow rate, we determined when this measure converged with a contemporary control and also when it returned to baseline values. Both approaches showed that sprinklers could continue to cool cows after treatment ended, but yielded different information about the effectiveness of each flow rate and timing. When comparing against the contemporary control, body temperature stayed lower for all sprinkler flow rates until converging around $2 \mathrm{~h}$ after treatment. Body temperature ultimately decreased (albeit more gradually in warmer weather) after the end of the control treatment, but increased over time following the sprinkler treatments. These patterns are likely due to cows in our study having access to shade after treatment: relative to no cooling resources, shade alone can reduce body temperature but is less effective than sprinklers (e.g., Kendall et al., 2007). Others have 
similarly found that body temperature remained lower than controls for $1.5 \mathrm{~h}$ (Brown-Brandl et al., 2010) or even 2 to $4 \mathrm{~h}$ after spraying stopped (Araki et al., 1985; Kendall et al., 2007). Before converging with the control, body temperature in our sprinkler treatments returned to baseline values. This happened sooner for lower flow rates: 8 min after spraying ended when we applied $0.4 \mathrm{~L} / \mathrm{min}$, but 32 and 47 min after we used 1.3 and $\geq 4.5 \mathrm{~L} / \mathrm{min}$, respectively. When we applied $\geq 1.3 \mathrm{~L} / \mathrm{min}$, wind extended the duration, similar to when sprinklers are combined with fans (as reviewed by Collier et al., 2006). Others have similarly found body temperature to reach a nadir between 30 and $60 \mathrm{~min}$ after spraying stopped (Araki et al., 1985; Flamenbaum et al., 1986; Kendall et al., 2007).

\section{Cooling Determinants and Mechanisms}

Our study is the first to directly compare the cooling effectiveness of different flow rates, as well as droplet sizes. We predicted that with spray duration held constant, higher flow rates would provide better cooling, and that within a given flow rate, larger droplets would cool more effectively (as they are less likely to evaporate before reaching cattle and might better penetrate the hair coat to the skin). However, we found that only flow rate determined cooling: droplet size had no effect on any measure of heat load, even though average droplet size differed by 1.2- to 1.5-fold for nozzles that delivered a given amount of water.

When cows did not have shade or sprinklers, physiological measures of heat load increased during the 1-h treatment. Compared with this unsprayed control, all sprinkler flow rates resulted in lower respiration rate and skin temperature on directly wetted body parts. However, in other comparisons, flow rates $\geq 1.3 \mathrm{~L} / \mathrm{min}$ cooled more effectively than $0.4 \mathrm{~L} / \mathrm{min}$. This is in line with our predictions regarding flow rate. In pilot tests with $1.3 \mathrm{~L} / \mathrm{min}$, we calibrated the spray application duration according to the common industry recommendation to wet cattle only until water begins to drip from their sides (e.g., Edstrom, 2011). When at least this amount was applied, we speculate that water dripping from the cows may have provided cooling that was additional to evaporation by drawing some heat away from their bodies through fluid convection. Indeed, when $\geq 1.3 \mathrm{~L} / \mathrm{min}$ was used, respiration rate was at least $8 \%$ lower relative to the control immediately following the first spray application, before evaporation had much time to occur $(\leq 1 \mathrm{~min}$ after the water was turned off). Similarly, immediately after 90 and $10 \mathrm{~min}$ of continuous spray, this measure was 60 and $29 \%$ lower, respectively, relative to controls (Kendall et al., 2007; Schütz et al., 2011). However, it is possible that water evaporating from the cows, the ground, or droplets in the air could also explain reductions in respiration rate that occurred while the spray was activated. The degree and speed of cooling provided by fluid convection compared with evaporation from various sources requires further study.

\section{Water Use Efficiency}

Because $0.4 \mathrm{~L} / \mathrm{min}$ cooled less effectively than the higher flow rates when applied for the same amount of time, we will compare only 1.3 and $\geq 4.5 \mathrm{~L} / \mathrm{min}$ when discussing the most efficient option. Over the course of the 1 -h treatment, the 1.3 and $\geq 4.5 \mathrm{~L} / \mathrm{min}$ flow rates delivered a total of 15.6 and $\geq 54.0 \mathrm{~L}$ of water, respectively, of which about 5.5 and $\geq 16.4 \mathrm{~L}$, respectively, directly wetted the cows (as estimated from our model of a cow's back). Overall, $1.3 \mathrm{~L} / \mathrm{min}$ balanced cooling effectiveness and water usage most efficiently. Although $\geq 4.5 \mathrm{~L} / \mathrm{min}$ was the only treatment that reduced skin temperature on the upper leg relative to baseline, only relatively minor additional physiological benefits were associated with applying more than $1.3 \mathrm{~L} / \mathrm{min}$. For example, relative to baseline, $\geq 4.5 \mathrm{~L} / \mathrm{min}$ lowered respiration rate by 4 more breaths/min than $1.3 \mathrm{~L} / \mathrm{min}$ ( -13 vs. -9 breaths/min, respectively), but this meant that each additional liter of water beyond $15.6 \mathrm{~L}$ decreased respiration rate by only $\leq 0.1$ breaths $/ \mathrm{min}$. Similarly, $\geq 4.5 \mathrm{~L} / \mathrm{min}$ kept body temperature below baseline values after the end of treatment for $15 \mathrm{~min}$ longer than $1.3 \mathrm{~L} / \mathrm{min}$ did $(47$ vs. $32 \mathrm{~min}$, respectively), but each additional liter of water extended the duration by only $\leq 23 \mathrm{~s}$. We found similar patterns when evaluating how well each flow rate reduced skin temperature on the side, shoulder, and lower leg relative to baseline, compared against water usage. Relative to the control, both flow rates resulted in lower body temperature and skin temperature on all parts of the body.

When $1.3 \mathrm{~L} / \mathrm{min}$ was applied for $3 \mathrm{~min}$, the actual volume that wetted each cow $(1.4 \mathrm{~L}$, estimated from our model of a cow's back), was similar to guidelines that suggest applying 0.9 to $1.3 \mathrm{~L} /$ cow per cycle when spraying intermittently (Brouk et al., 2003, 2005; Washington State University Veterinary Medicine Extension, 2008; Bailey et al., 2012). However, more research is needed to evaluate whether the most efficient amount of water required for cooling cows in a hot, dry climate changes with varying time spent at the feed bunk, including longer periods that will allow for the measurement of production responses such as feed intake and milk yield, and also to quantify how flow rate and droplet size influence spray drift (which affects how much cows and feed are wetted). 


\section{CONCLUSIONS}

Our study provides experimental evidence for how much water is needed to efficiently cool lactating dairy cows in regions with hot, dry summers. Flow rate, rather than droplet size, was the main determinant of cooling effectiveness when cattle were restrained for $1 \mathrm{~h}$ under intermittent spray (4 applications of 3 min each). The flow rate that best balanced cooling effectiveness against potable water usage was $1.3 \mathrm{~L} / \mathrm{min}$ (resulting in about $1.4 \mathrm{~L} /$ application directly wetting each cow). When at least this amount was used, respiration rate and skin temperature decreased relative to baseline at the end of the 1-h treatment, and body temperature stayed below baseline for at least $30 \mathrm{~min}$ beyond the end of treatment. Applying additional water did little to improve cooling effectiveness. Finally, we found that sprinklers rapidly affect physiological measures of heat load: changes occurred during the first 3-min spray application for skin temperature, at min 4 for respiration rate, and at min 13 for body temperature (before additional spray was applied).

\section{ACKNOWLEDGMENTS}

We are grateful to those who helped with data collection: Erin Mintline, Jordan Alarcon, Sarah Watkins, and Aaron Yoder, all affiliated with University of California-Davis (UC Davis) at the time of the study. Many thanks also to Joy Mench, Neil Willits, Ken Giles, the managers, staff, and interns of the UC Davis Dairy Teaching and Research Facility, the Animal Science Farm Crew, Todd Donaldson with W. A. Westgate Co. (Davis, CA), and USDA multi-state research project W2173. We gratefully acknowledge the infrastructure support of the Department of Animal Science, the College of Agricultural and Environmental Sciences, and the UC-Davis California Agricultural Experiment Station.

\section{REFERENCES}

Araki, C. T., R. M. Nakamura, L. W. G. Kam, and N. L. Clarke. 1985. Diurnal temperature patterns of early lactating cows with milking parlor cooling. J. Dairy Sci. 68:1496-1501.

Arkin, H., E. Kimmel, A. Berman, and D. Broday. 1991. Heat transfer properties of dry and wet furs of dairy cows. Trans. ASAE 34:2550-2558.

Armstrong, D. V. 1994. Heat stress interaction with shade and cooling. J. Dairy Sci. 77:2044-2050.

ASABE. 2009. Spray Nozzle Classification by Droplet Spectra. Standard S572.1. American Society of Agricultural and Biological Engineers, St. Joseph, MI.

Avendaño-Reyes, L., J. A. Hernández-Rivera, F. D. Álvarez-Valenzuela, U. Macías-Cruz, R. Díaz-Molina, A. Correa-Calderón, P. H. Robinson, and J. G. Fadel. 2012. Physiological and productive responses of multiparous lactating Holstein cows exposed to shortterm cooling during severe summer conditions in an arid region of Mexico. Int. J. Biometeorol. 56:993-999.

Bailey, T., J. Sheets, and M. Bryan. 2012. Mechanics of Heat Abatement. Elanco Animal Health, Greenfield, IN.

Bath, D. L., and S. J. Strasser. 1990. A computer program for formulating nutritional and economical rations for dairy operations. Vet. Med. 85:1334, 1336-1340, 1342.

Benjamini, Y., and Y. Hochberg. 1995. Controlling the false discovery rate: A practical and powerful approach to multiple testing. J. R. Stat. Soc. Ser. B Stat. Methodol. 57:289-300.

Bollwein, H., H. H. D. Meyer, J. Maierl, F. Weber, U. Baumgartner, and R. Stolla. 2000. Transrectal Doppler sonography of uterine blood flow in cows during the estrous cycle. Theriogenology 53:1541-1552.

Brouk, M. J., D. Armstrong, J. Smith, M. VanBaale, D. Bray, and J. Harner. 2005. Evaluating and selecting cooling systems for different climates. Pages 33-40 in Proc. West. Dairy Man. Conf., Reno, NV. Western Dairy Management Conference, Manhattan, KS.

Brouk, M. J., J. F. Smith, and J. P. Harner. 2003. Effectiveness of cow cooling strategies under different environmental conditions. Pages 141-154 in Proc. West. Dairy Man. Conf., Reno, NV. Western Dairy Management Conference, Manhattan, KS.

Brown-Brandl, T. M., R. A. Eigenberg, and J. A. Nienaber. 2010. Water spray cooling during handling of feedlot cattle. Int. J. Biometeorol. 54:609-616.

Chen, J. M., K. E. Schütz, and C. B. Tucker. 2013. Dairy cows use and prefer feed bunks fitted with sprinklers. J. Dairy Sci. 96:50355045.

Collier, R. J., G. E. Dahl, and M. J. VanBaale. 2006. Major advances associated with environmental effects on dairy cattle. J. Dairy Sci. 89:1244-1253.

Cuttle, L., M. Kempf, P. Liu, O. Kraychuk, and R. M. Kimble. 2010. The optimal duration and delay of first aid treatment for deep partial thickness burn injuries. Burns 36:673-679.

De Rensis, F., and R. J. Scaramuzzi. 2003. Heat stress and seasonal effects on reproduction in the dairy cow-A review. Theriogenology 60:1139-1151.

DeVries, T. J., M. A. G. von Keyserlingk, D. M. Weary, and K. A. Beauchemin. 2003. Measuring the feeding behavior of lactating dairy cows in early to peak lactation. J. Dairy Sci. 86:3354-3361.

Doble, S. J., G. A. Matthews, I. Rutherford, and E. S. E. Southcombe. 1985. A system for classifying hydraulic and other atomisers into categories of spray quality. Pages 1125-1133 in Proc. Brit. Crop Protection Conf. Weeds, Brighton, UK. British Crop Protection Council, London, UK.

Edstrom. 2011. Edstrom: Cooling Systems for Dairy Cattle. Catalog No. SB-000003 Rev E. Edstrom Industries, Waterford, WI.

Finch, V. A. 1986. Body temperature in beef cattle: Its control and relevance to production in the tropics. J. Anim. Sci. 62:531-542.

Flamenbaum, I., D. Wolfenson, M. Mamen, and A. Berman. 1986. Cooling dairy cattle by a combination of sprinkling and forced ventilation and its implementation in the shelter system. J. Dairy Sci. 69:3140-3147.

Gallardo, M. R., S. E. Valtorta, P. E. Leva, M. C. Gaggiotti, G. A. Conti, and R. F. Gregoret. 2005. Diet and cooling interactions on physiological responses of grazing dairy cows, milk production and composition. Int. J. Biometeorol. 50:90-95.

Gaughan, J. B., T. L. Mader, S. M. Holt, and A. Lisle. 2008. A new heat load index for feedlot cattle. J. Anim. Sci. 86:226-234.

Gebremedhin, K. G., P. E. Hillman, C. N. Lee, R. J. Collier, S. T. Willard, J. D. Arthington, and T. M. Brown-Brandl. 2008. Sweating rates of dairy cows and beef heifers in hot conditions. Trans. ASABE 51:2167-2178.

Gebremedhin, K. G., and B. X. Wu. 2002. Simulation of sensible and latent heat losses from wet-skin surface and fur layer. J. Therm. Biol. 27:291-297.

Granzin, B. C. 2006. Cooling and forage supplementation of grass-fed Holstein cows during hot conditions. Trop. Anim. Health Prod. $38: 141-150$. 
Hahn, G. L. 1985. Management and housing of farm animals in hot environments. Pages 151-174 in Stress Physiology of Livestock. Vol. II: Ungulates. M. K. Yousef, ed. CRC Press Inc., Boca Raton, FL.

Hernández-Rivera, J. A., F. D. Álvarez-Valenzuela, A. Correa-Calderón, U. Macías-Cruz, J. G. Fadel, P. H. Robinson, and L. Avendaño-Reyes. 2011. Effect of short-term cooling on physiological and productive responses of primiparous Holstein cows exposed to elevated ambient temperatures. Acta Agric. Scand. A Anim. Sci. 61:34-39.

Igono, M. O., H. D. Johnson, B. J. Steevens, G. F. Krause, and M. D. Shanklin. 1987. Physiological, productive, and economic benefits of shade, spray, and fan system versus shade for Holstein cows during summer heat. J. Dairy Sci. 70:1069-1079.

Keister, Z. O., K. D. Moss, H. M. Zhang, T. Teegerstrom, R. A Edling, R. J. Collier, and R. L. Ax. 2002. Physiological responses in thermal stressed Jersey cows subjected to different management strategies. J. Dairy Sci. 85:3217-3224.

Kelly, C. F., and T. E. Bond. 1971. Bioclimatic factors and their measurement. Page 77 in A Guide to Environmental Research on Animals. National Academies Press, Washington, DC.

Kendall, P. E., G. A. Verkerk, J. R. Webster, and C. B. Tucker. 2007. Sprinklers and shade cool cows and reduce insect-avoidance behavior in pasture-based dairy systems. J. Dairy Sci. 90:3671-3680.

Kimmel, E., H. Arkin, D. Broday, and A. Berman. 1991. A model of evaporative cooling in a wetted hide. J. Agric. Eng. Res. 49:227241.

Kirch, B. H., G. E. Aiken, and D. E. Spiers. 2008. Temperature influences upon vascular dynamics in cattle measured by Doppler ultrasonography. J. Therm. Biol. 33:375-379.

Kume, S., K. Nonaka, T. Oshita, and T. Kozakai. 2010. Evaluation of drinking water intake, feed water intake and total water intake in dry and lactating cows fed silages. Livest. Sci. 128:46-51.

Legrand, A., K. E. Schütz, and C. B. Tucker. 2011. Using water to cool cattle: Behavioral and physiological changes associated with voluntary use of cow showers. J. Dairy Sci. 94:3376-3386.

Means, S. L., R. A. Bucklin, R. A. Nordstedt, D. K. Beede, D. R. Bray, C. J. Wilcox, and W. K. Sanchez. 1992. Water application rates for a sprinkler and fan cooling system in hot, humid climates. Trans. ASAE 8:375-379.

Meyer, D., B. Reed, C. Batchelder, I. Zallo, P. L. Ristow, G. Higginbotham, M. Arana, T. Schultz, D. D. Mullinax, and J. Merriam. 2006. Water use and winter liquid storage needs at Central Valley dairy farms in California. Trans. ASAE 22:121-126.

Meyer, M. J., J. F. Smith, J. P. Harner, J. E. Shirley, E. C. Titgemeyer, and M. J. Brouk. 2002. Performance of lactating dairy cattle in three different cooling systems. Trans. ASAE 18:341-345.

Mitlöhner, F. M., J. L. Morrow, J. W. Dailey, S. C. Wilson, M. L. Galyean, M. F. Miller, and J. J. McGlone. 2001. Shade and water misting effects on behavior, physiology, performance, and carcass traits of heat-stressed feedlot cattle. J. Anim. Sci. 79:2327-2335.

Montoya, R. E., R. A. Bucklin, R. A. Nordstedt, J. v. Horn Jr., and D. R. Bray. 1995. Factors affecting water usage in fan and sprinkler cooling systems for dairy cattle. Trans. ASAE 11:125-130.
NRC. 1989. Nutrient Requirements of Dairy Cattle. 6th rev. ed. National Academies Press, Washington, DC.

Osborn, T. G., S. P. Schmidt, D. N. Marple, C. H. Rahe, and J. R. Steenstra. 1992. Effect of consuming fungus-infected and fungusfree tall fescue and ergotamine tartrate on selected physiological variables of cattle in environmentally controlled conditions. J. Anim. Sci. 70:2501-2509.

Rosenstock, T., S. Smukler, and T. Cavagnaro. 2006. California agricultural landscapes and climate change. Pages 3-12 in Climate Change: Challenges and Solutions for California Agricultural Landscapes. T. Cavagnaro, L. Jackson, and K. Scow, ed. California Climate Change Center, Sacramento, CA.

SAS Institute. 2014. SAS/STAT 13.2 User's Guide. SAS Institute Inc., Cary, NC.

Schütz, K. E., A. R. Rogers, N. R. Cox, J. R. Webster, and C. B. Tucker. 2011. Dairy cattle prefer shade over sprinklers: Effects on behavior and physiology. J. Dairy Sci. 94:273-283.

Spray Analysis and Research Services. 1993. Data sheet 11825-50: TK FloodJet wide angle flat spray tips volume median diameter versus pressure curves, capacities TK-VS2 thru TK-VS10. Spraying Systems Co., Wheaton, IL.

Spray Analysis and Research Services. 1995. Data sheet 11825-64: TK FloodJet wide angle flat spray tips capacities TK-.50 thru TK-1.5. Spraying Systems Co., Wheaton, IL.

Spraying Systems Co. 2013. Industrial Hydraulic Spray Products. Catalog No. 75. Spraying Systems Co., Wheaton, IL.

Stoline, M. R. 1981. The status of multiple comparisons: Simultaneous estimation of all pairwise comparisons in one-way ANOVA designs. Am. Stat. 35:134-141.

Stull, C. L., L. L. McV. Messam, C. A. Collar, N. G. Peterson, A. R. Castillo, B. A. Reed, K. L. Andersen, and W. R. VerBoort. 2008 Precipitation and temperature effects on mortality and lactation parameters of dairy cattle in California. J. Dairy Sci. 91:45794591

USDA. 2010. Facility characteristics and cow comfort on U.S. Dairy Operations, 2007. UDSA-Animal and Plant Health Inspection Service-Veterinary Services, Centers for Epidemiology and Animal Health (USDA-APHIS-VS, CEAH), Fort Collins, CO

Valtorta, S. E., and M. R. Gallardo. 2004. Evaporative cooling for Holstein dairy cows under grazing conditions. Int. J. Biometeorol. 48:213-217.

Vitali, A., M. Segnalini, L. Bertocchi, U. Bernabucci, A. Nardone, and N. Lacetera. 2009. Seasonal pattern of mortality and relationships between mortality and temperature-humidity index in dairy cows. J. Dairy Sci. 92:3781-3790.

Washington State University Veterinary Medicine Extension. 2008. Ag animal health spotlight: Heat stress. Washington State University, Pullman, WA.

Wheelock, J. B., R. P. Rhoads, M. J. VanBaale, S. R. Sanders, and L. H. Baumgard. 2010. Effects of heat stress on energetic metabolism in lactating Holstein cows. J. Dairy Sci. 93:644-655. 